\title{
GSTU43 gene involved in ALA-regulated redox homeostasis, to maintain coordinated chlorophyll synthesis of tomato at low temperature
}

Tao Liu ${ }^{1,2,3+}$, Qingjie Du ${ }^{1,2,3+}$, Suzhi Li, ${ }^{1,2,3}$, Jianyu Yang ${ }^{1,2,3}$, Xiaojing $\mathrm{Li}^{1,2,3}$, Jiaojiao $\mathrm{Xu}^{1,2,3}$, Pengxiang Chen ${ }^{1}$, Jianming $\mathrm{Li}^{1,2,3}$ and Xiaohui $\mathrm{Hu}^{1,2,3^{*}}$

\begin{abstract}
Background: Exogenous 5-aminolevulinic acid (ALA) positively regulates plants chlorophyll synthesis and protects them against environmental stresses, although the protection mechanism is not fully clear. Here, we explored the effects of ALA on chlorophyll synthesis in tomato plants, which are sensitive to low temperature. We also examined the roles of the glutathione S-transferase (GSTU43) gene, which is involved in ALA-induced tolerance to oxidation stress and regulation of chlorophyll synthesis under low temperature.

Results: Exogenous ALA alleviated low temperature caused chlorophyll synthesis obstacle of uroporphyrinogen III (UROIII) conversion to protoporphyrin IX (Proto IX), and enhanced the production of chlorophyll and its precursors, including endogenous ALA, Proto IX, Mg-protoporphyrin IX (Mg-proto IX), and protochlorophyll (Pchl), under low temperature in tomato leaves. However, ALA did not regulate chlorophyll synthesis at the level of transcription. Notably, ALA up-regulated the GSTU43 gene and protein expression and increased GST activity. Silencing of GSTU43 with virus-induced gene silencing reduced the activities of GST, superoxide dismutase, catalase, ascorbate peroxidase, and glutathione reductase, and increased the membrane lipid peroxidation; while fed with ALA significant increased all these antioxidase activities and antioxidant contents, and alleviated the membrane damage.

Conclusions: ALA triggered GST activity encoded by GSTU43, and increased tomato tolerance to low temperatureinduced oxidative stress, perhaps with the assistance of ascorbate- and/or a glutathione-regenerating cycles, and actively regulated the plant redox homeostasis. This latter effect reduced the degree of membrane lipid peroxidation, which was essential for the coordinated synthesis of chlorophyll.
\end{abstract}

Keywords: 5-aminolevulinic acid (ALA), Antioxidant, Chlorophyll synthesis, Glutathione S-transferase (GSTU43) gene, Low temperature, Solanum lycopersicum (tomato)

\section{Background}

Plants exposed to low temperature exhibit a short-term stress response involved modification of gene expression and levels of plant hormones, increased cross-talk signaling, and accumulation of osmolytes and antioxidants,

\footnotetext{
* Correspondence: hxh1977@163.com

${ }^{\dagger}$ Tao Liu and Qingjie Du contributed equally to this work.

${ }^{1}$ College of Horticulture, Northwest A \& F University, Yangling 712100,

Shaanxi, China

${ }^{2}$ Key Laboratory of Protected Horticultural Engineering in Northwest, Ministry of Agriculture, Yangling 712100, Shaanxi, China

Full list of author information is available at the end of the article
}

presumably to protect against long-term damage [1]. Extended exposure to low temperature damages DNA and protein, causes lipid peroxidation, and results in general physiological and metabolic disturbances that reduce growth and vigor [2].

It is well-known that exogenous application of 5-aminolevulinic acid (ALA) improves plant tolerance to environmental stress [3-9]. This compound is also the precursor to porphyrins, which are, in turn, the precursors to plant pigments, including heme and chlorophyll; as such, application of ALA increased the chlorophyll content of plants $[8,10,11]$. In a

(C) The Author(s). 2019 Open Access This article is distributed under the terms of the Creative Commons Attribution 4.0 International License (http://creativecommons.org/licenses/by/4.0/), which permits unrestricted use, distribution, and 
previous study, we observed that ALA improved perception of, and tolerance to, oxidative stress imposed by low temperature. We attributed this to the accumulation of glutathione (GSH) and ascorbate (AsA) [12].

The tripeptide glutathione (GSH; composed of $\gamma$-GluCys-Gly) is an antioxidant with a central role in the regulation of redox balance and signaling [13-16]. Plants contain several GSH-dependent detoxifying enzymes [17, 18], most notably glutathione S-transferases (EC 2.5.1.18, GSTs). GSTs are an evolutionarily ancient, large, and diverse family. GSTs have catalytic functions and non-catalytic functions (such as binding and transport of secondary metabolites and hormones), which related to their structural dynamics [19].

Many studies have shown that GSTs play crucial roles in mediating plant perception of, and tolerance to, abiotic stress. For example, induction of GSTs by salicylic acid (SA) [20] or their over-expression [21] sustained tomato redox homeostasis when plants were exposed to salt stress. Also, when the drought-tolerant Prosopis juliflora (PjGSTU1) gene was introduced into tobacco, its peroxidase activity reduced excess reactive oxygen species (ROS) and maintained the redox balance in drought-stressed plants [22]. In other studies, the over-expression of a tobacco U class of GSTs elevated the GST activity, apparently increasing the levels of antioxidants sufficiently to permit tobacco seedlings [23] to cope with salt and chilling stress and to permit rice plants to cope with low temperature stress [24]. The non-catalytic functions of GSTs may also be important in stress tolerance. GSTs could bind and/ or conjugate metabolites such as porphyrins [25], phytohormones [26], and other secondary metabolites [27], and then transport them to perform function or protect against cellular oxidation [19].

The metabolism of porphyrins, central to the synthesis of chlorophyll and heme, is carefully regulated in the chloroplast. In healthy cells, the integrated membrane system and conjugated protein provide guarantee for chlorophyll synthesis [28]. However, the membranes and conjugated protein of stressed cells may be damaged by peroxides, and under this circumstance porphyrins could leak into the cytosol $[19,25,29]$. If so, they would be oxidized to the lipophilic and phytotoxic protoporphyrin, exacerbating the already damaging effect of peroxide accumulation in stressed cells $[25,29]$. The ZmGSTU1 of maize, bound porphyrinogens that had leaked from chloroplasts under oxidative stress, preventing their auto oxidation and apparently protecting the cells from oxidative stress [29].

Tomatoes are sensitive to low temperatures $\left(8^{\circ} \mathrm{C}-15^{\circ} \mathrm{C}\right)$, in the winter and early spring in China. Low temperature can severely limit the growth and yield of tomatoes. Many studies have illustrated that exogenously applied ALA reduced ROS accumulation by increasing antioxidant ability under abiotic stress [30-33]. Our preliminary studies showed that ALA induced early $\mathrm{H}_{2} \mathrm{O}_{2}$ signaling under normal conditions, which then interacted with JA, induced the downstream NO, regulated the redox state, resulting in elevated antioxidant capacity and photosynthesis in tomato plants under low temperature [12, 34]. This was accompanied by ALA-induced up-regulation of the GSTU43 gene (Additional file 2: Fig. S1), which encodes a GST. These results inspired us to ask: What is the relationship between redox homeostasis and porphyrin synthesis regulated by exogenous ALA during low temperature stress? What is the role of GSTU43 in the maintenance of redox homeostasis at low temperature? So, in this study, we first assessed the effect of exogenous ALA on chlorophyll synthesis and GST activity encoded by GSTU43 in tomato leaves. And we further explored whether GSTU43 involved in ALA-mediated redox status and alleviation of membrane lipid peroxidation, which was crucial for the coordinated chlorophyll synthesis.

\section{Methods \\ Treatment with exogenous ALA and Gabaculine}

Tomato (Solanum lycopersicum cv. Jinpeng no. 1, which is sensitive to low temperature stress) seeds (purchase from Xi'an Jinpeng Seedlings Co., Ltd. Shaanxi, China.) were used in this study. Seedlings cultivation was according to our previous study [12]. When the fifth true leaves were completely expanded, plants of similar appearance were selected for the experiments.

We wished to compare the effects of exogenous ALA on chlorophyll synthesis, expression of GSTU43 and GST activity in plants exposed to low and normal temperature. Plants were sprayed with $6 \mathrm{~mL}$ either distilled water or 25 mg. $\mathrm{L}^{-1}$ ALA (Sigma-Aldrich, St. Louis, MO, USA) solution [12], containing a few drops of Tween-20, $1.5 \mathrm{~h}$ before the night. Twelve hours later, half of ALA-treated and untreated plants were kept at normal temperatures $\left(25^{\circ} \mathrm{C} /\right.$ $18^{\circ} \mathrm{C}$, day/night) while the rest of the plants were exposed to a low-temperature regime: $15^{\circ} \mathrm{C}$ during the photoperiod and $8{ }^{\circ} \mathrm{C}$ during the dark, with the same relative humidity and light period as the normal-temperature plants.

To determine whether exogenous ALA-induced GSTU43 up-regulation and GST activity is due to endogenous ALA. The tomato leaves were pretreated with $100 \mu \mathrm{M}$ Gabaculine (GAB, inhibition of ALA synthesis that inactivates glutamate-1-semialdehyde aminotransferase) [35, 36]. After $8 \mathrm{~h}$, the leaves were sprayed with distilled water or 25 $\mathrm{mg} \cdot \mathrm{L}^{-1}$ ALA. Twelve hours later, the plants were exposed to low temperatures. After $24 \mathrm{~h}$ low temperatures, the GSTU43 gene expression and protein levels, and GST activity were measured.

\section{VIGS plants and experiments}

To prepare the pTRV2-GSTU43 vectors, a 294 bp fragment of GSTU43 was amplified with PCR using the forward 
primer GCTCTAGAATGCCAGTAATGGGGAAAGC and the reverse primer GGGGTACCTCTTGGCGGTAAATATTCCTTG; the primers contained XbaI and KpnI restriction sites. The PCR fragment was inserted into the $\mathrm{XbaI}$ and KpnI site of pTRV2 vector. The pTRV2-GSTU43 VIGS constructs were confirmed by sequencing. Then, Agrobacterium tumefaciens strain GV3101 was transformed with pTRV2-GSTU43 as described by Cheng et al. [37]. Agrobacterium-mediated virus infection was performed as described of Ekengren et al. [38], when two cotyledons of tomato seedlings (cv. Jinpeng no. 1), cultivated as our previous study [12], completely expanded. An Agrobacterium culture carrying an empty pTRV2 vector was also infiltrated into a set of plants that served as a control. The inoculated plants were maintained at $20-22^{\circ} \mathrm{C}$ in a growth chamber with relative humidity of $60 \% \pm 5 \%$, and a two-phase photoperiod of $12.5 \mathrm{~h}$ with a PPFD of $350 \mu \mathrm{mol}$ photons $\cdot \mathrm{m}^{-2} \cdot \mathrm{s}^{-1}$ followed by $1.5 \mathrm{~h}$ with a PPFD of $50 \mu \mathrm{mol}$ photons $\mathrm{m}^{-2}$. $\mathrm{s}^{-1}$ ); the photoperiod was followed by a 10-h dark period. The temperature and light period were set according to the description of Cheng et al. [37] and our preliminary experiment. After 35 days, the gene silencing efficiency was assessed with quantitative real-time PCR (qRT-PCR) before the plants were used in assays. And then, plants of similar appearance were selected for the experiments.

The plants were pre-treated with exogenous ALA, then exposed to normal condition $\left(22^{\circ} \mathrm{C} / 20^{\circ} \mathrm{C}\right.$, day/night $)$ or low temperature $\left(15^{\circ} \mathrm{C} / 8^{\circ} \mathrm{C}\right.$, day/night) $12 \mathrm{~h}$ later. After $24 \mathrm{~h}$ of low temperature, malondialdehyde (MDA) content, relative electrical conductivity (REC), $\mathrm{H}_{2} \mathrm{O}_{2}$ content, maximal quantum yield of PSII photochemistry $(\mathrm{Fv} / \mathrm{Fm})$, antioxidase and antioxidants levels, expression of GSTU43 gene of VIGS plants were measured. Frozen samples were collected for the measurement of $\mathrm{MDA}, \mathrm{H}_{2} \mathrm{O}_{2}$, antioxidases, antioxidants, and gene expression, while fresh samples were used for the $\mathrm{REC}$ and $\mathrm{Fv} / \mathrm{Fm}$ analysis. Samples for plant dry weight were taken $6 \mathrm{~d}$ after the start of the low temperature treatment.

Leaf samples were collected at different times after the start of the temperature treatment, frozen immediately in liquid nitrogen, and stored at $-80^{\circ} \mathrm{C}$ until needed. Fresh leaf samples were harvested for measuring the chlorophyll and related compounds, plant dry weight, and $\mathrm{Fv} / \mathrm{Fm}$ and REC. All the experiments were repeated for three times, and three independent biological replicates for each time.

\section{Measurement of plant dry weight}

Plants were rinsed three times with distilled water, oven dried at $105^{\circ} \mathrm{C}$ for $15 \mathrm{~min}$, and then at $75^{\circ} \mathrm{C}$ for $72 \mathrm{~h}$ to obtain dry weights.

\section{Chlorophyll synthesis analysis}

Chlorophyll was extracted from the fifth fully expanded leaf in acetone, ethanol, and water (4.5: 4.5: $1, \mathrm{v} / \mathrm{v} / \mathrm{v})$ and pigments were analyzed spectrophotometrically based on the absorbance at 450, 645, and $663 \mathrm{~nm}$ [39]. The content of ALA was determined according to the methods of Morton [40]. The porphobilinogen (PBG) and UROIII content were measured according to the methods of Bogorad [41]. The Proto IX, Mg-protoporphyrin IX (Mg-proto IX) and protochlorophyll (Pchl) were all carried out according to the methods of Hodgins and Van Huystee [42]. All the details for determining these chlorophyll precursors above were described in our previous studies [43].

\section{Membrane lipid peroxidation assays}

The $\mathrm{H}_{2} \mathrm{O}_{2}$ content was obtained via monitoring the absorbance at $412 \mathrm{~nm}$ [44], as described in our previous study [12]. Using the methods of Hodges et al. [45], and Zhou and Leul [46] to determine the MDA content and $\mathrm{REC}$, respectively. Fv/Fm was assayed as described in our previous study [12, 47], and the plants were subjected to dark for $30 \mathrm{~min}$ before determination.

\section{Antioxidant assays}

The activity of superoxide dismutase (SOD; EC 1.15.1.1) was conducted using the method of Giannopolitis and Ries [48]. The activities of catalase (CAT; EC 1.11.1.6), glutathione reductase (GR; EC 1.6.4.2), ascorbate peroxidase (APX; EC 1.11.1.11), monodehydroascorbate reductase (MDHAR; EC 1.6.5.4), dehydroascorbate reductase (DHAR; EC 1.8.5.1), and the contents of glutathione and ascorbate were assayed as described in our previous study [12, 49]. The GST activity was measured using GSH-ST assay kit (Nanjing Jiancheng Bioengineering Institute, Nanjing, China) following the supplier's instruction.

\section{Gene expression analyses}

For RNA sequencing experiments, the tomato leaves, treated with ALA or/ and temperature, were collected and frozen immediately in liquid nitrogen, and stored at $-80^{\circ} \mathrm{C}$ until needed. And then, the RNA sequencing were carried out using Illumina High-Seq platform at Biomarker Technologies Corporation (Beijing, China). The total RNA extracted and qRT-PCR analyses were conducted according to our previous descriptions [34] using two different reference genes, actin 7 and GAPDH [50], and the relative gene expression was calculated following Livak and Schmittgen [51]. The gene specific primers are listed in Additional file 1: Table S1.

\section{Protein extraction and western blotting}

The protein extraction and western blotting according to the methods of Zhou et al. [52] with a modification. Briefly, for protein extraction, tomato leaves, collected $24 \mathrm{~h}$ after low temperature treatment, were ground in liquid nitrogen, and homogenized in extraction 
buffer (50 mM Tris-HCl, pH 7.5, containing, $150 \mathrm{mM}$ $\mathrm{NaCl}, 2 \mathrm{mM}$ EDTA-Na $2,10 \%$ glycerol, $1 \%$ Triton X-100, $1 \mathrm{mM}$ PMSF and $1 \mathrm{mM}$ DTT). The extracts were centrifuged at $12,000 \mathrm{~g}$ for $20 \mathrm{~min}$, and the extracted protein was heated at $95^{\circ} \mathrm{C}$ for $15 \mathrm{~min}$, then separated using $10 \%$ SDS-PAGE. For western blotting, the proteins on the SDS-PAGE gel were transferred to a polyvinylidenefluoride membrane. The membrane was blocked for $12 \mathrm{~h}$ at $4{ }^{\circ} \mathrm{C}$ in $1 \times$ BLOK BSA in PBS [Sangon Biotech (Shanghai) Co., Ltd], then incubated for $4 \mathrm{~h}$ in antibody dilution buffer and a rabbit anti-GSTU43 polyclonal antibody [Genscript (Nanjing) Co., Ltd.], or a rabbit antiactin polyclonal antibody (Abcam). And then the membrane was incubated with a goat antirabbit HRP-conjugated antibody (Cell Signaling Technology). Accumulation of actin and GSTU43 were quantified using Image Lab 6.0 software (Bio-Rad, Hercules, CA, USA).

\section{Statistical analysis}

All data were subjected to analysis of variance (ANOVA) using SAS 8.0 software (SAS Institute, Cary, NC, USA). Significant difference was assessed using Tukey's test at a significance level of $P<0.05$, unless stated otherwise.

\section{Results}

ALA regulated chlorophyll synthesis in low temperaturestressed tomato leaves

ALA is a precursor in the chlorophyll biosynthetic pathway. Exogenous application of ALA has been shown to increase the chlorophyll content in leaves of crop species $[6,33,53]$, so we began this study by measuring the effect of exogenous ALA on the chlorophyll content and other related compounds (precursors) in low temperaturestressed tomato leaves compared to leaves from unstressed plants (Figs. 1 and 2).

In plants grown in normal temperature $\left(25^{\circ} \mathrm{C} / 18^{\circ} \mathrm{C}\right)$, exogenous ALA had no obvious effect on either chlorophyll or endogenous ALA levels, while there were more PBG, UROIII, Proto IX, Mg-proto IX, and Pchl at 72 and $96 \mathrm{~h}$ in ALA-treated plants than in untreated controls. Low temperature treatment $\left(15^{\circ} \mathrm{C} / 8^{\circ} \mathrm{C}\right)$ by itself decreased the amounts of chlorophyll and most of the precursors, but dramatically increased PBG, UROIII, and the ratio of Chl a/ b, apparent $48 \mathrm{~h}$ after treatment was started. However, when low temperature-stressed plants received exogenous ALA, there was markedly less PBG and UROIII, and more of the other precursors and chlorophyll after $48 \mathrm{~h}$ than the low temperature-stressed plants alone.

We performed qRT-PCR to analyze the genes expression of the key enzymes involved in chlorophyll biosynthetic
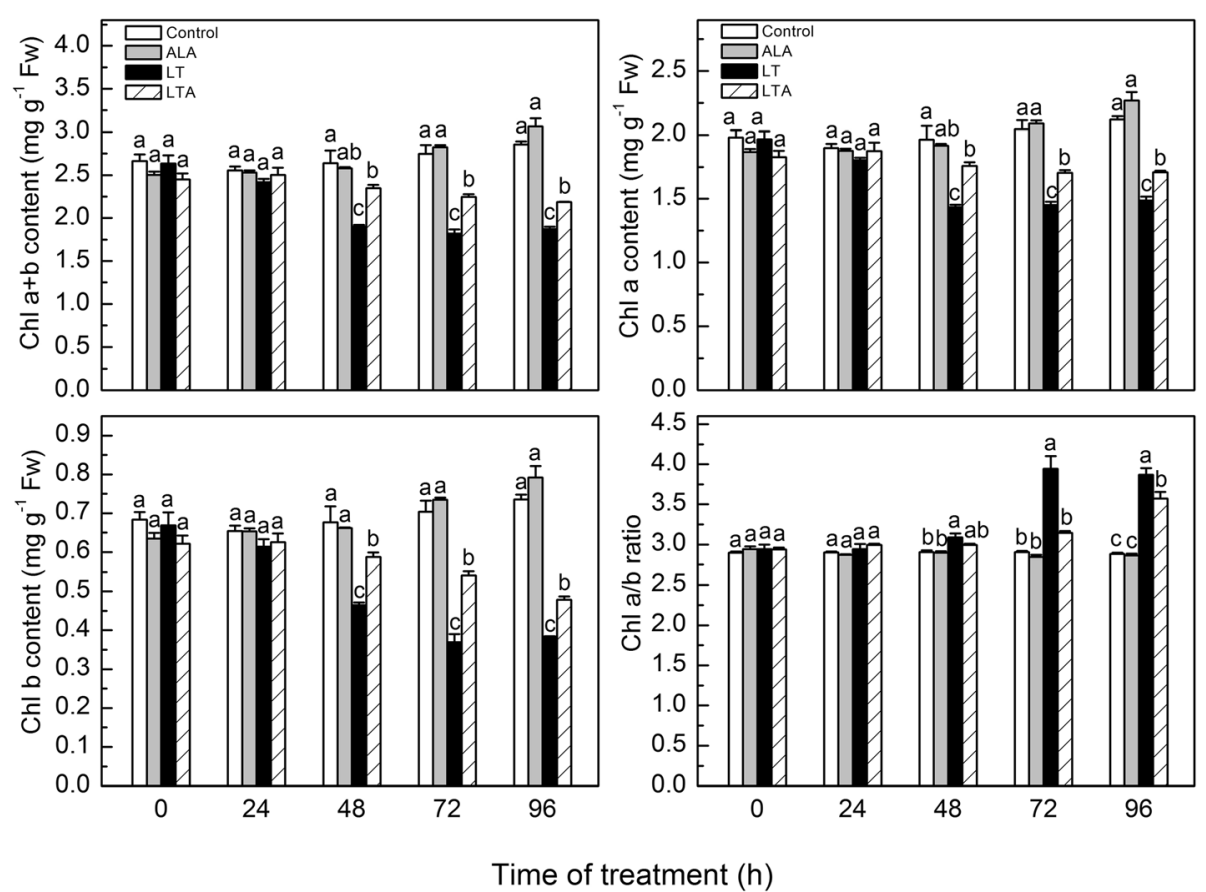

Fig. 1 ALA induced kinetic changes of chlorophyll content in tomato leaves within $96 \mathrm{~h}$ after imposition of low temperature. The tomato leaves treated with distilled water or $25 \mathrm{mg} \cdot \mathrm{L}^{-1}$ ALA then exposed to normal condition (control and ALA) or low temperature (LT and LTA) $12 \mathrm{~h}$ later. The chlorophyll (Chl) content were measured when the low temperature started. Data are expressed as the mean \pm standard error of three independent biological replicates. The experiments were repeated for three times. Different letters above the bars indicate a significant difference determined by one-way ANOVA with Tukey's test $(P<0.05)$. Fw, fresh weight 

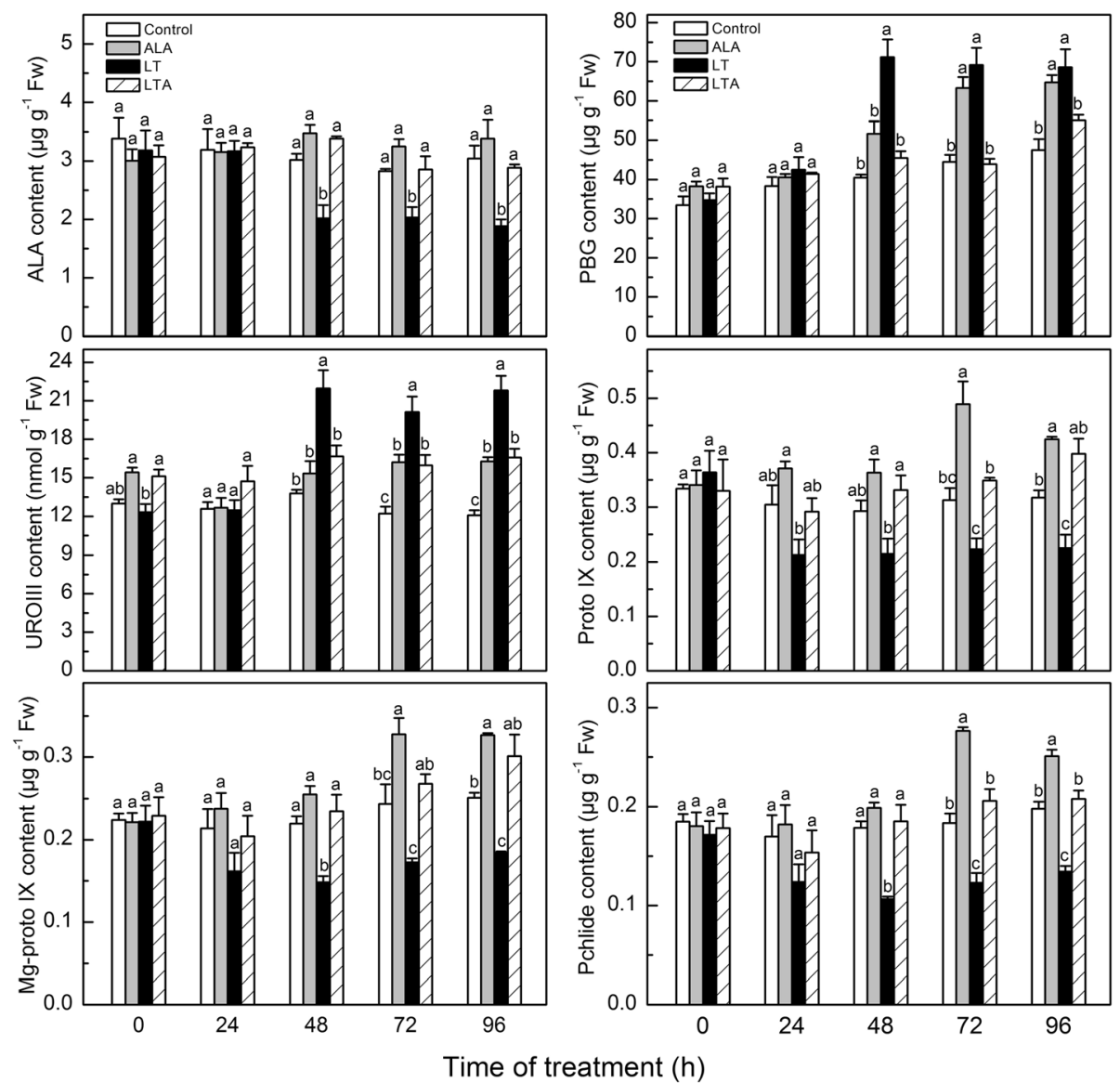

Fig. 2 ALA induced kinetic changes of chlorophyll precursors in the chlorophyll biosynthetic pathway in tomato leaves within $96 \mathrm{~h}$ after imposition of low temperature. The tomato leaves treated with distilled water or $25 \mathrm{mg} \cdot \mathrm{L}^{-1} \mathrm{ALA}$ then exposed to normal condition (control and ALA) or low temperature (LT and LTA) $12 \mathrm{~h}$ later. The precursor content were measured when the low temperature started. Data are expressed as the mean \pm standard error of three independent biological replicates. The experiments were repeated for three times. Different letters above the bars indicate a significant difference determined by one-way ANOVA with Tukey's test $(P<0.05)$. ALA, 5-aminolevulinic acid; PBG, porphobilinogen; UROIII, uroporphyrinogen III; Proto IX, protoporphyrin IX; Mg-proto IX, Mg-protoporphyrin IX; and Pchl, protochlorophyll

pathway. Under normal condition, application of ALA had no obvious effect on aminolevulinic dehydratase $(A L A D)$ expression at any time, but dramatically elevated the transcription of other genes at different times: specifically, expression of porphobilinogen deaminase $(P B G D)$ was elevated before $6 \mathrm{~h}$, uroporphyrinogen decarboxylase (UROD) at $3 \mathrm{~h}$ and $48 \mathrm{~h}$, coproporphyrinogen III oxidase (CPOX) and protoporphyrinogen IX oxidase $(P P O X)$ at $0 \mathrm{~h}, 3 \mathrm{~h}$, and $48 \mathrm{~h}, \mathrm{Mg}$-protoporphyrin IX methyltransferase (CHLM) within $3 \mathrm{~h}$, protochlorophyllide oxidoreductase $(P O R)$ at 0 $\mathrm{h}$, and chlorophyll synthase $(C H L G)$ at $0 \mathrm{~h}, 24 \mathrm{~h}$, and $48 \mathrm{~h}$ (Fig. 3). Expression of chlorophyllide a oxygenase $(C A O)$ at $0 \mathrm{~h}, 3 \mathrm{~h}, 6 \mathrm{~h}$, and $24 \mathrm{~h}, U R O D$ at $12 \mathrm{~h}, C P O X$ at $12 \mathrm{~h}$ and 24 $\mathrm{h}$, PPOX at $6 \mathrm{~h}$ and $12 \mathrm{~h}$, respectively, in ALA-treated leaves were lower than in the control. When exogenous ALA was supplied before low temperature stress, the genes expression of PBGD, CPOX, PPOX, CHLM, POR, and CHLG were significantly up-regulated at $0 \mathrm{~h}$, and then decreased expression of these genes after $3 \mathrm{~h}$, while UROD transcript was up-regulated at $3 \mathrm{~h}$ and down-regulated at $12 \mathrm{~h}$ and $24 \mathrm{~h}$, respectively, compared to low temperaturestressed plants alone.

These results showed that low temperature disrupted chlorophyll synthesis and hindered URO III conversion to Proto IX, and that exogenous ALA counteracted the disruptive effect of low temperature. However, this pattern was not apparent in gene expression, indicating that ALA may regulate chlorophyll synthesis at a level other than transcription $[54,55]$.

\section{ALA positively induced the GSTU43 gene and protein expression, and GST activity in tomato at low temperature}

Glutathione S-transferases regulate the redox balance and improve plant oxidation resistance [19]. We observed that GSTU43 was significantly up-regulated by ALA using RNA-seq in tomato (Additional file 2: Figure S1), and we also verified the expression of GSTU43 and 


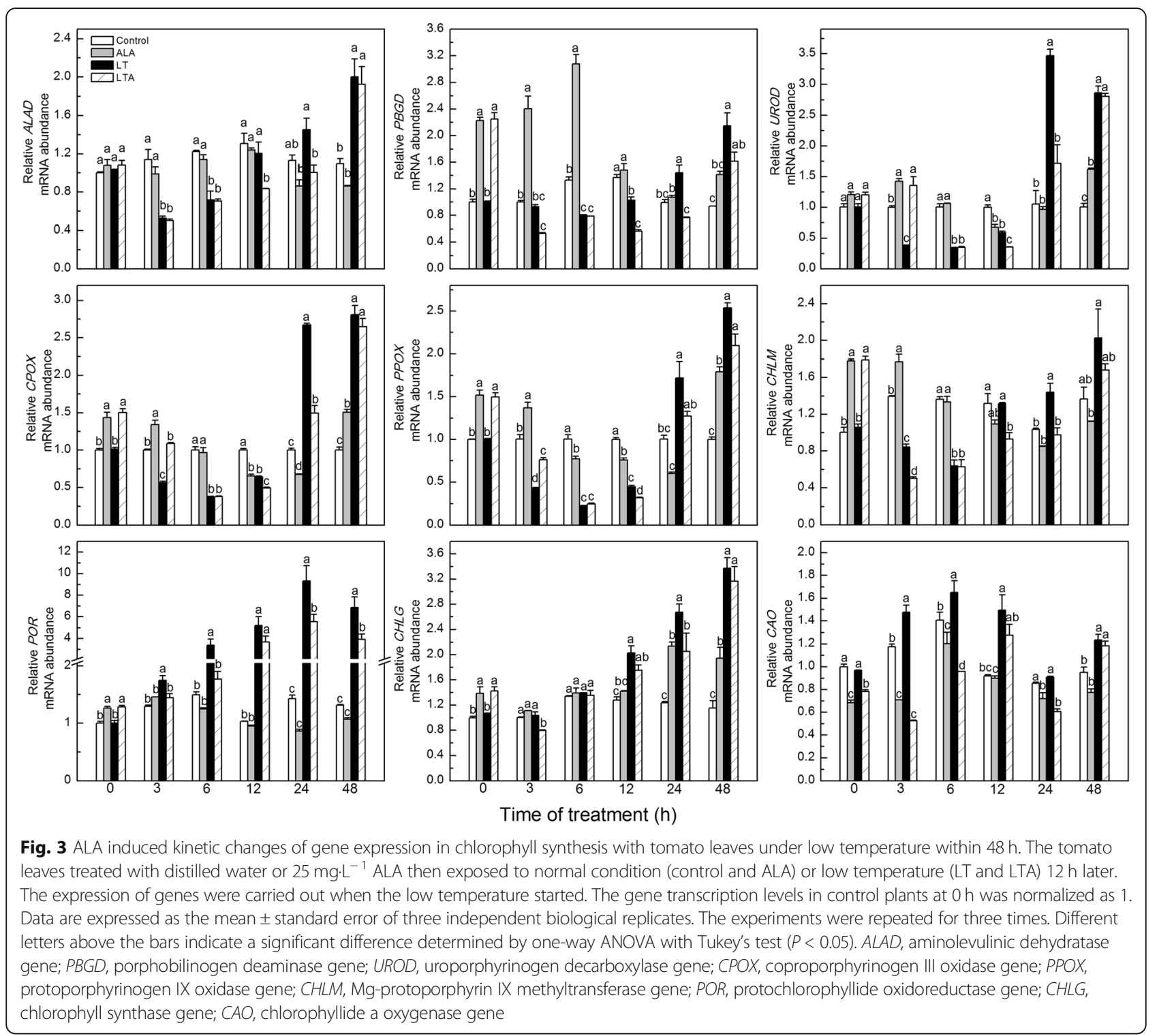

its associated GST activity. In this study, ALA significantly raised the GSTU43 expression since $6 \mathrm{~h}$, and increased GST activity was apparent at $24 \mathrm{~h}$ and $48 \mathrm{~h}$ (Fig. 4a and b). This elevation was apparent in both temperature treatments. In normal temperatures, ALA increased GSTU43 transcription by 121 and $224 \%$, and the activity of GST by 18.9 and $45.9 \%$, at $24 \mathrm{~h}$ and $48 \mathrm{~h}$, respectively. When the plants were low temperaturestressed, GSTU43 expression was increased 154 and $132 \%$, and GST activity was increased 33.2 and $33.6 \%$ at $24 \mathrm{~h}$ and $48 \mathrm{~h}$, respectively.

Compared with control plants under normal or low temperature stress alone, fed with ALA dramatically improved GSTU43 gene and protein expression, and GST activity (Fig. 4c, d and e). Compared with control plants, $\mathrm{GAB}$ treatment further provoked a significant increase of GSTU43 gene and protein expression, and GST activity by 290,212 and $67.8 \%$, respectively, under normal temperature; while GAB plus low temperature triggered an increase of GSTU43 gene and protein expression, and GST activity 603, 108 and 46.9\% increase, respectively, compared to low temperature treatment alone. GAB plus ALA treatment dramatically decreased the GAB triggered GSTU43 gene and protein expression, and GST activity, under normal or low temperature.

\section{GSTU43 is involved in ALA- induced low temperature tolerance}

We silenced GSTU43 with VIGS to assess the function of GSTU43 in ALA-induced low temperature tolerance. The average silence efficiency was about 68.9\% (Additional file 3: Figure S2a). Under low temperature, the dry weight of low 

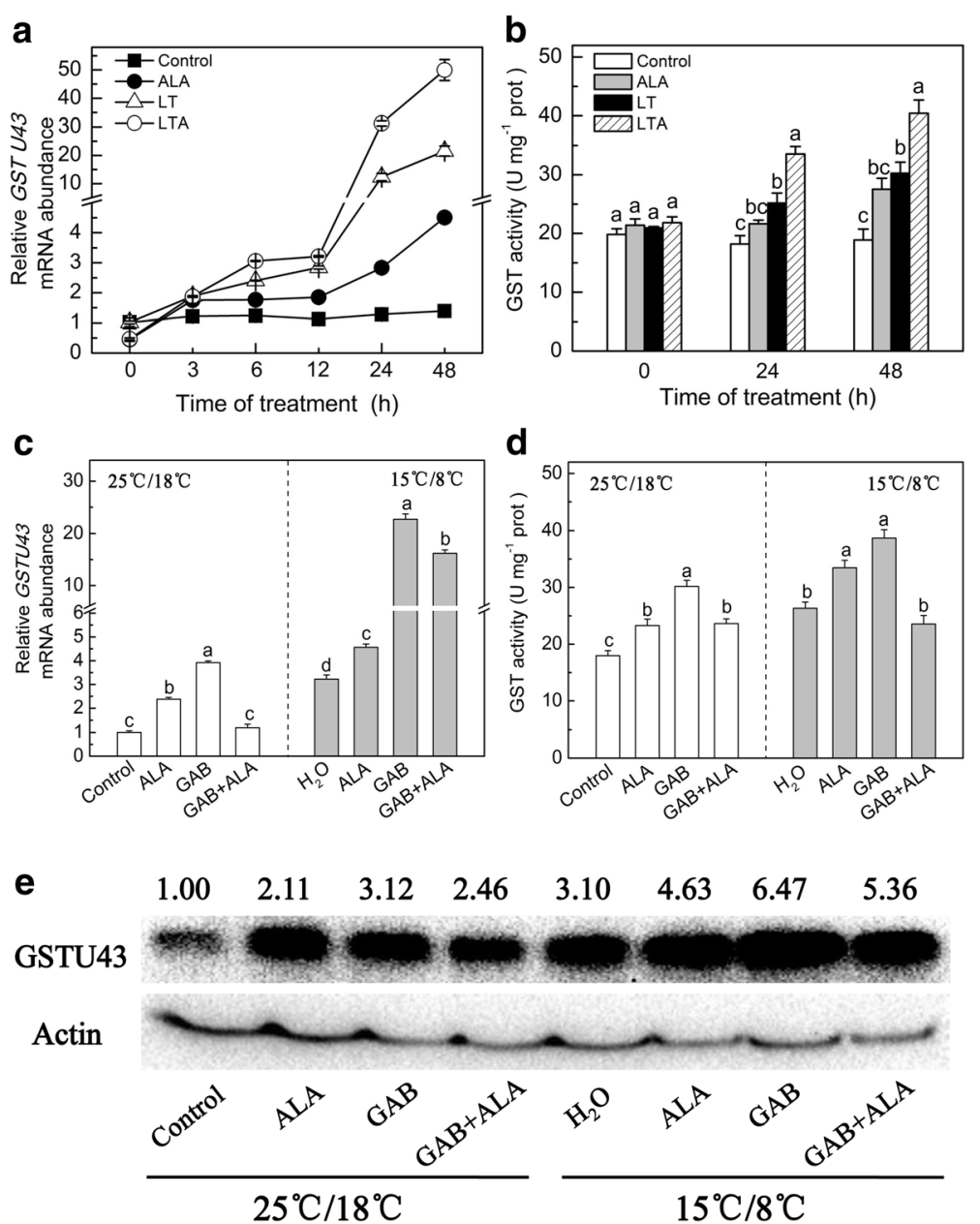

Fig. 4 ALA induced changes of glutathione S-transferase (GSTU43) gene and protein expression and GST activity in tomato leaves under low temperature within $48 \mathrm{~h}$. The tomato leaves treated with distilled water or $25 \mathrm{mg} \cdot \mathrm{L}^{-1} \mathrm{ALA}$ then exposed to normal condition (control and ALA) or low temperature (LT and LTA) $12 \mathrm{~h}$ later. The expression of GSTU43 (the gene transcription levels in control plants at $0 \mathrm{~h}$ was normalized as 1 ) (a) and GST activity (b) were carried out when the low temperature started. The tomato leaves were pretreated with $100 \mu \mathrm{M}$ Gabaculine (GAB, inhibition of ALA synthesis that inactivates glutamate-1-semialdehyde aminotransferase). After $8 \mathrm{~h}$, the leaves were sprayed with distilled water or $25 \mathrm{mg} \cdot \mathrm{L}^{-1} \mathrm{ALA}$. Twelve hours later, the plants were exposed to low temperatures. After $24 \mathrm{~h}$ low temperatures, the GSTU43 gene expression (the gene transcription levels in control plants at $24 \mathrm{~h}$ was normalized as 1) (c) and GST activity (d), and protein levels (e) were measured. Data are expressed as the mean \pm standard error of three independent biological replicates. The experiments were repeated for three times. Different letters above the bars indicate a significant difference determined by one-way ANOVA with Tukey's test $(P<0.05)$

temperature-stressed, GSTU43 silenced plants was $15.0 \%$ less than the pTRV plant, and supplementing the GSTU43 silenced, low temperature-stressed plants with ALA restored the dry weight to the pTRV level (Additional file 3: Figure S2b).

We also assessed membrane lipid peroxidation damage. We observed no effect of exogenous ALA on levels of MDA and REC, or on Fv/Fm in pTRV-GSTU43 plants grown at normal temperatures (Fig. 5). Low temperatures resulted in accumulation of MDA, elevated REC, and reduced $\mathrm{Fv} / \mathrm{Fm}$ compared to normal temperature. The differences were most striking in the low temperaturestressed, pTRV-GSTU43 plants; ALA reversed the effects of silencing and restored the values to those of the pTRV low temperature-stressed plants (Fig. 5).

\section{Silencing of GSTU43 compromised ALA- induced enhancement in antioxidant capacity}

Redox homeostasis is important for plant growth and development [56, 57], and we have shown that ALA positively regulates the redox state of tomato via the accumulation of $\mathrm{GSH}$ and AsA, mediated by $\mathrm{H}_{2} \mathrm{O}_{2}$ [12]. We further investigated the role of GSTU43 in ALAinduced oxidative stress tolerance of tomato under low temperature by assessing the expression of GSTU43, and the level of antioxidant and activities of antioxidases. 


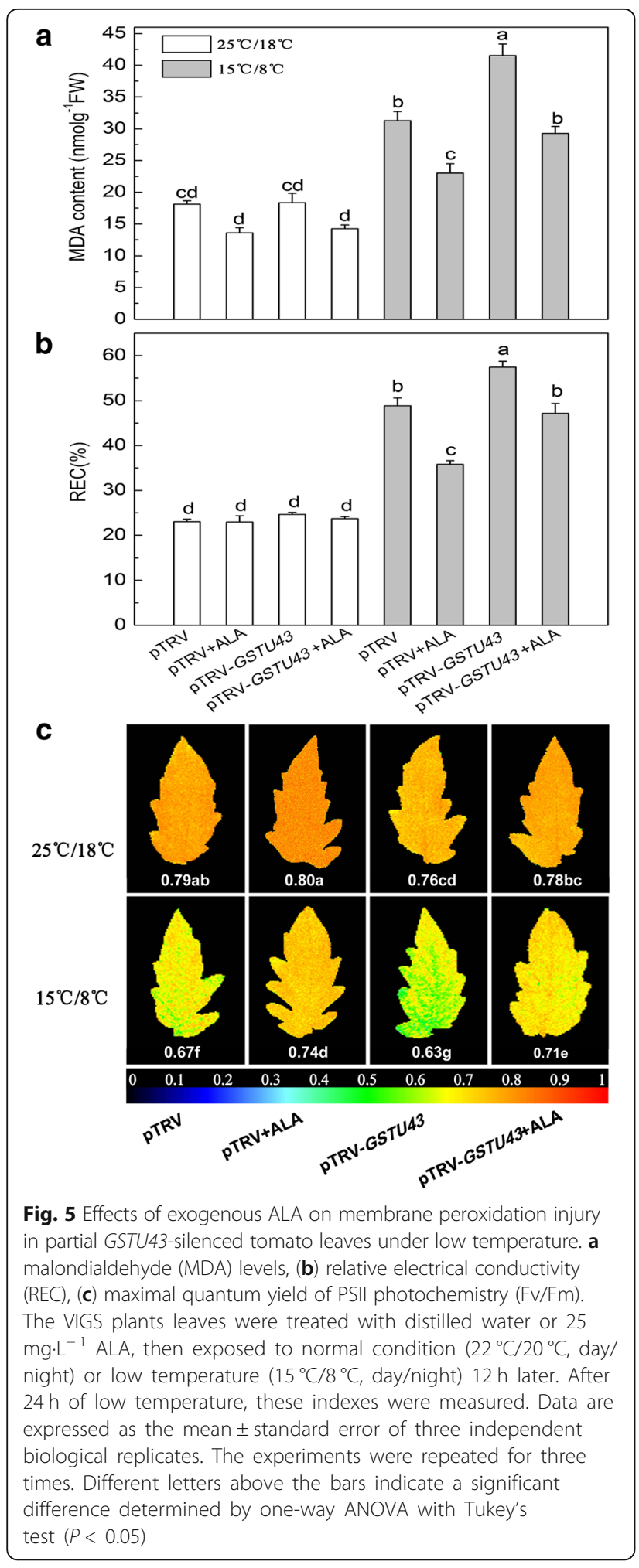

Under normal temperatures, ALA treated plants showed higher GSTU43 expression and GST activity than the plants without ALA treated (Fig. 6).
We next examined these parameters in low temperaturestressed plants. Expression of GSTU43 and GST activity in pTRV-GSTU43 plants exposed to low temperature was significantly less than in low temperature-stressed pTRV plants. In low temperature-stressed pTRV-GSTU43 plants treated with ALA, GSTU43 expression increased by $335 \%$, and GST activity increased by $167 \%$, respectively, compared to pTRV-GSTU43 plants not receiving ALA.

Under normal condition, pTRV-GSTU43 plants compared to pTRV plants had much less CAT and GR activity, and ALA application slightly restored these activities (Fig. 7). Under low temperature, pTRV-GSTU43 plants compared to PTRV plants had greater MDHAR and DHAR activity, and more ascorbate [measured as AsA and dehydroascorbate (DHA), combined], more glutathione [measured as GSH and glutathion disulfide (GSSG) combined], and slightly lower SOD, CAT, APX and GR activities, and slightly lower ratio of GSH/ GSSG (Figs. 7 and 8). When the low temperature stressed pTRV-GSTU43 plants were supplied exogenous ALA, there was a significant increase in all these antioxidase activities and antioxidant contents, compared to the same plants without ALA treatment.

\section{Discussion}

Plants live in a changeable environment, which requires them to cope with a variety of environmental stress [58]. Tomatoes are a warm weather crop, and during production in some climates, they may be exposed to low temperature in winter and early spring. This can negatively affect their growth and development [59]. Alleviating the plant cold tolerance in different periods via plant growth regulators is a feasible approach. For example, GABA improved cold tolerance of tea plants by inducing amino biosynthesis, and carbon and nitrogen metabolism [60]. Interestingly, recent research showed that melatonin application at grain filling in maternal plants could improve the wheat progeny seedling chilling tolerance by regulating the redox homeostasis and photosynthesis [61]. This study of the low temperature stress response of tomatoes was prompted in part by preliminary results that exogenous ALA improved the tolerance of tomatoes to low temperature by regulating GSH and AsA pools [12]. In addition, many studies have demonstrated that exogenous ALA enhances chlorophyll content of crops exposed to low temperature [6, 10, 62].

Previous studies showed that exogenous ALA promoted the content of chlorophyll precursors in Arabidopsis [63] and Kentucky bluegrass [64]. We observed this promoting effect of ALA in tomato, also, as shown in Fig. 2 for plants in normal temperature.

It has also been noted that when plants were exposed to stress, firstly, the membranes of stressed cells may be damaged by peroxides. And then, the free porphyrinogens leaked into the cytosol from the damaged membranes and were oxidized to the lipophilic and phytotoxic 

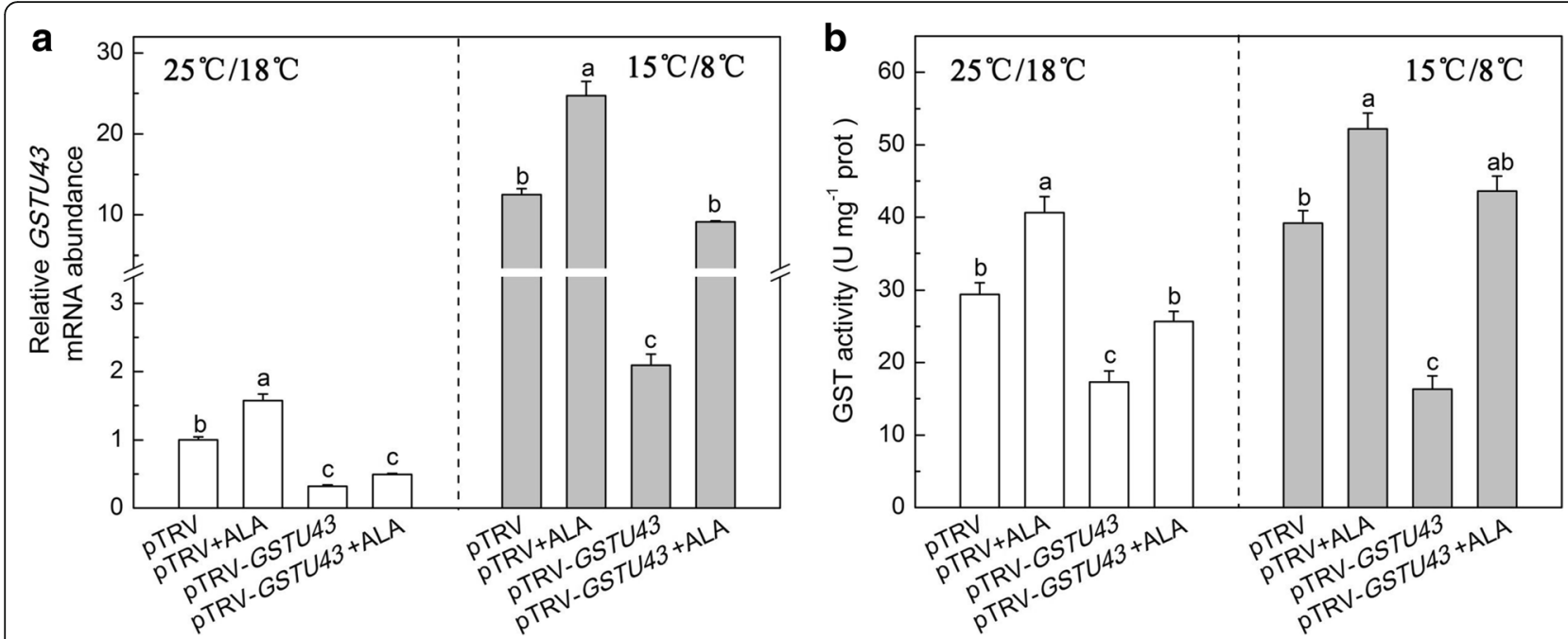

Fig. 6 ALA induced GSTU43 expression and GST activity in partial GSTU43-silenced plants exposed to low temperature. a GSTU43 expression. The gene transcription levels in pTRV plants under normal condition at $24 \mathrm{~h}$ was normalized as 1, (b) GST activity. The VIGS plants leaves were treated with distilled water or $25 \mathrm{mg} \cdot \mathrm{L}^{-1} \mathrm{ALA}$, then exposed to normal condition $\left(22^{\circ} \mathrm{C} / 20^{\circ} \mathrm{C}\right.$, day/night) or low temperature $\left(15^{\circ} \mathrm{C} / 8^{\circ} \mathrm{C}\right.$, day/night) $12 \mathrm{~h}$ later. After $24 \mathrm{~h}$ of low temperature, these indexes were measured. Data are expressed as the mean \pm standard error of three independent biological replicates. The experiments were repeated for three times. Different letters above the bars indicate a significant difference determined by one-way ANOVA with Tukey's test $(P<0.05)$

protoporphyrin, which may cause more serious oxidative damage [25, 29]. In addition to the damage of binding protein and key enzymes in chlorophyll synthesis which affected the chlorophyll synthesis [65], this may serve as a mechanism for the plants to protect themselves against the damaging effect of protoporphyrin. We suggest that this self-preservation mechanism may account for our observation that UROIII was not converted to Proto IX in low temperature-stressed plants, leading not only to reduce Proto IX, but to lower levels of ALA, Mg-Proto-IX, Pchl, and chlorophyll than in the plants at normal temperature (Figs. 1 and 2).

Application of ALA alleviated the effects of low temperature on chlorophyll synthesis, accompanied by elevation of the porphyrin level. It may be that the increased amount of porphyrin in the ALA-treated plants regulated nuclear gene expression, operating in signaling [66], which then enhances plant antioxidant capacity [67], and reduces membrane lipid peroxidation of the tomato under low temperature [12]. This would permit coordinated chlorophyll synthesis (Figs. 1 and 2). Based on our results with chlorophyll synthesis related genes expression, it may be that the ALA-mediated effects on chlorophyll biosynthesis are regulated at the translation or posttranslational levels, but not at the transcriptional levels (Fig. 3) [55], which still needed further researches. Similar results were also reported for ALA-regulated chlorophyll synthesis in oilseed rape [8] and Arabidopsis [54]. Redox homeostasis is important for coordinated chlorophyll synthesis [54]. Studies have shown that GSTs regulate plant redox balance by improving its antioxidant and avoiding autoxidation during stress via conjugation of leaked porphyrinogens in the cytosol $[19,25,68]$.

In this study, ALA treatment up-regulated the GSTU43 gene and protein expression and GST activity (Fig. 4, Additional file 2: Figure S1). Inhibition of endogenesis ALA via GAB did not weaken the GSTU43 gene and protein expression, and GST activity, on the contrary, illustrated a maximum value under both temperature. However, GAB plus ALA treatment declined these trends. This said, exogenous ALA triggered GST activity may be mainly related to the hormones signals or transcription factor, such as ERF and MYB [19], induced by exogenous ALA, but not completely dependent on endogenesis ALA. In other words, the mechanism by which the exogenous ALA activated GSTU43 transcription and GST activity was different from that of the endogenous ALA. However, GAB, which may be as a harmful chemical inducer [19], had other effects than reducing the endogenous ALA level, and these other effects override the impact of the reduced ALA level on the expression of GSTU43 and GST activity. Simultaneously, GAB stimulated high GSTU43 transcript, and then provoked the GSTU43 protein expression and GST activity to cope with its own damage effects. Still, this was an interesting and confusing result, which needs further research.

Although low temperature alone induced GST activity, simultaneously decreased the activities of CAT and GR, and the ratio of reduced GSH, which eventually leads to the imbalance of redox and membrane lipid peroxidation (Figs. 5, 6, 7, and 8). The damaged cell membrane may influence the proteases which bind to the thylakoid 


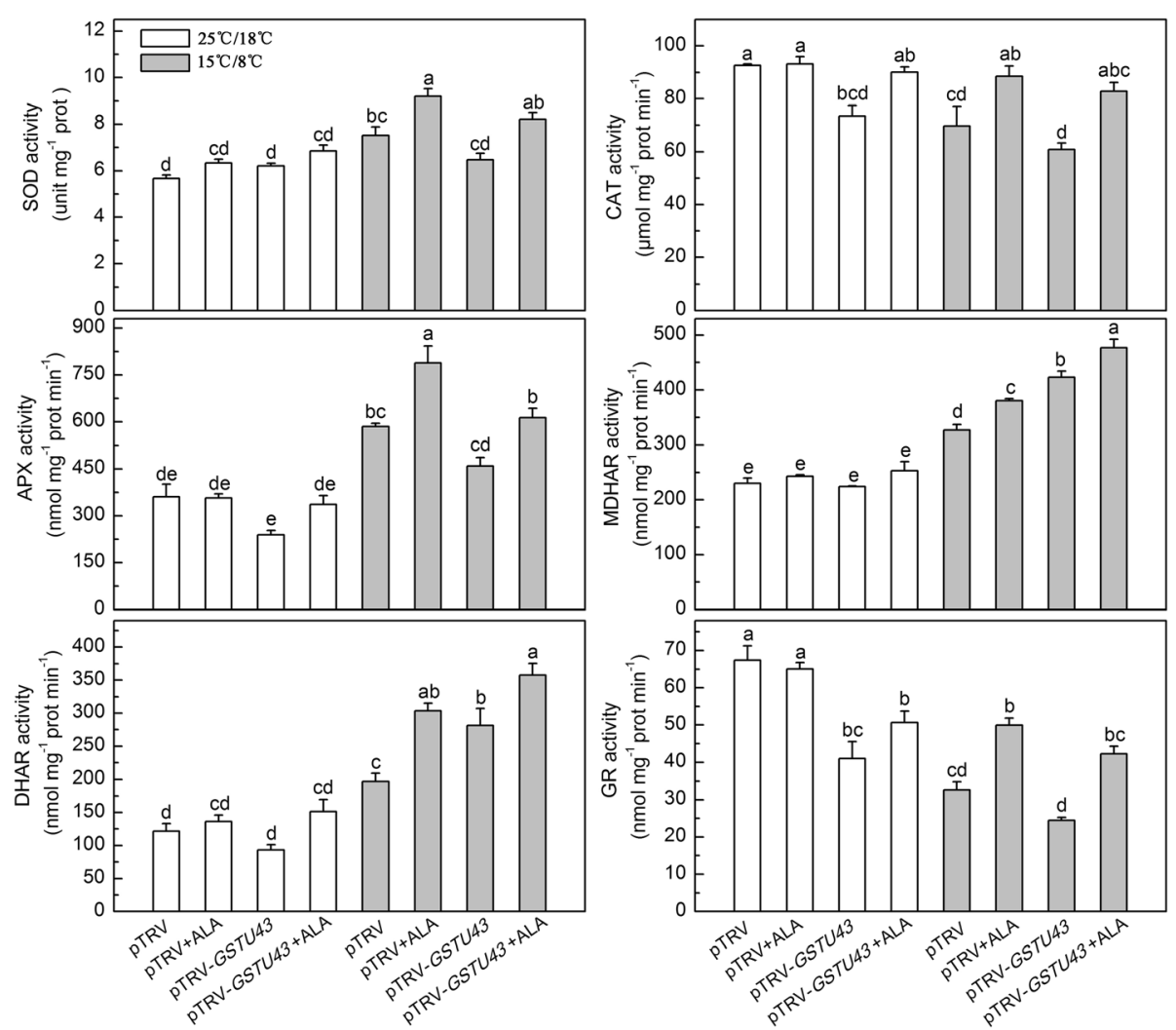

Fig. 7 Effects of exogenous ALA on antioxidase activities in partial GSTU43-silenced plants under low temperature. The VIGS plants leaves were treated with distilled water or $25 \mathrm{mg} \cdot \mathrm{L}^{-1} \mathrm{ALA}$, then exposed to normal condition $\left(22^{\circ} \mathrm{C} / 20^{\circ} \mathrm{C}\right.$, day/ night) or low temperature $\left(15^{\circ} \mathrm{C} / 8^{\circ} \mathrm{C}\right.$, day/ night) $12 \mathrm{~h}$ later. After $24 \mathrm{~h}$ of low temperature, these enzymes activities were measured. Data are expressed as the mean \pm standard error of three independent biological replicates. The experiments were repeated for three times. Different letters above the bars indicate a significant difference determined by one-way ANOVA with Tukey's test $(P<0.05)$. SOD, superoxide dismutase; CAT, catalase; APX, ascorbate peroxidase; MDHAR, monodehydroascorbate reductase; DHAR, dehydroascorbate reductase; GR, glutathione reductase

membrane and catalyze the porphyrin synthesis. And porphyrins may partly leak from the chloroplasts [25], leading to a high free porphyrin level which triggered autooxidation and then further caused serious membrane damage at the same time (Fig. 5), and reduced plant growth (Additional file 3: Figure S2b and c). Exogenous ALA significantly increased the activity of GST, which may cooperate with AsA-GSH cycle to regulate the redox homeostasis, and also reduced membrane lipid peroxidation damage by binding the over-accumulation and extravasation of porphyrins [25]. This may provide the redox homeostasis for chlorophyll synthesis [54].

Silencing of GSTU43 caused MDA accumulation, increased REC, and decreased the Fv/Fm. Exogenous ALA treatment reversed these effects in low temperature (Fig. 5). We considered that GSTU43 participated in removal of ROS that accumulated during low temperature stress of these plants.

In plants, $\mathrm{O}_{2}^{-}$is rapidly converted into $\mathrm{H}_{2} \mathrm{O}_{2}$ via SOD [69], which is, in turn, converted to $\mathrm{H}_{2} \mathrm{O}$ or $\mathrm{O}_{2}$ by an AsAand/or a GSH-regenerating cycle, and/or by CAT [70]. In present study, in low temperature, GSTU43 expression and GST activity of pTRV-GSTU34 plants compared to pTRV plants significantly decreased (Fig. 6), while the activities of SOD, CAT, APX, and GR were slightly decreased (Fig. 7). Apparently, low temperature stress caused ROS accumulation and membrane injury in pTRV-GSTU43 plants, mainly due to the inhibition of GST activity, although reduced activities of SOD, CAT, APX, and GR may have also contributed.

The observed high levels of AsA + DHA in low temperature-stressed pTRV-GSTU43 plants, compared with low temperature-stressed PTRV plants may have been due to the elevated activities of MDHAR and DHAR, which could reduce the DHA to AsA with the assistant of GSH, and ultimately caused the slight decline in the ratio of GSH/GSSG in pTRV-GSTU43 plants (Figs. 7 and 8). pTRV-GSTU43 plants plus exogenous ALA caused a dramatic enhancement of these enzyme activities, and increased the levels of GSH + GSSG and $\mathrm{AsA}+\mathrm{DHA}$, and the ratios of AsA/DHA and GSH/ GSSG, compared to pTRV-GSTU43 plants under low 

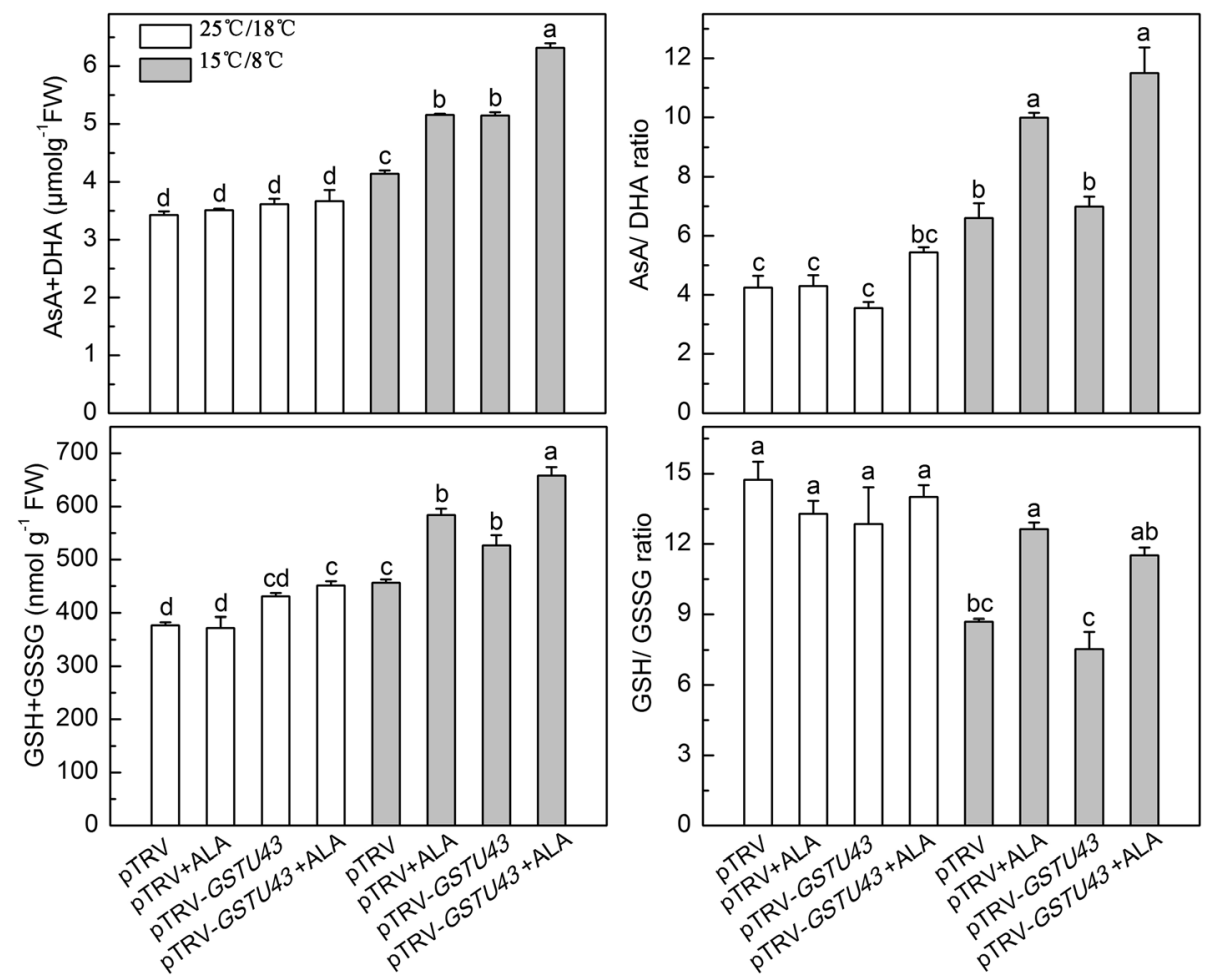

Fig. 8 Effects of exogenous ALA on the glutathione and ascorbate content in partial GSTU43-silenced plants under low temperature. The VIGS plants leaves were treated with distilled water or $25 \mathrm{mg} \cdot \mathrm{L}^{-1} \mathrm{ALA}$, then exposed to normal condition $\left(22^{\circ} \mathrm{C} / 20^{\circ} \mathrm{C}\right.$, day/ night) or low temperature $\left(15^{\circ} \mathrm{C} / 8^{\circ} \mathrm{C}\right.$, day/ night) $12 \mathrm{~h}$ later. After $24 \mathrm{~h}$ of low temperature, the glutathione and ascorbate were measured. Data are expressed as the mean \pm standard error of three independent biological replicates. The experiments were repeated for three times. Different letters above the bars indicate a significant difference determined by one-way ANOVA with Tukey's test $(P<0.05)$. GSH, glutathione; GSSG, glutathione disulfide; AsA, ascorbate; DHA, dehydroascorbate

temperature (Figs. 6, 7, and 8). We suggest that ALA alleviated the oxidative stress in pTRV-GSTU43 plants primarily through GST activity, with the cooperation of the AsA-GSH cycle, effecting redox balance for coordinated chlorophyll synthesis [54].

\section{Conclusions}

Low temperature disturbed the redox balance, and damaged the integrity and stability of the membrane, which may eventually affected the chlorophyll synthesis, and reduced the chlorophyll content. Exogenous ALA increased GST protein expression and enzyme activity, encoded by GSTU43, and appeared to play a central role in protecting the tomato plant from low temperatureinduced oxidative stress. It may operate with the assistance of the AsA- and/or a GSH-regenerating cycle, and actively regulated the plant redox homeostasis. This latter effect may, reduce the degree of membrane lipid peroxidation, which was essential for the coordinated synthesis of chlorophyll. Future studies may reveal the pathway how ALA induced GST outburst, which is crucial for increasing the plant's tolerance of oxidation stress and maintain a stable chlorophyll synthesis under low temperature.

\section{Additional files}

Additional file 1: Table S1. Gene-specific primers designed for qRTPCR. (DOCX $16 \mathrm{~kb})$

Additional file 2: Figure S1. ALA induced changes of glutathione Stransferase (GSTU43) gene using RNA-seq in tomato leaves under low temperature. The tomato leaves treated with distilled water or $25 \mathrm{mg} \cdot \mathrm{L}^{-1}$ ALA then exposed to normal condition (control and ALA) or low temperature (LT and LTA) $12 \mathrm{~h}$ later. After $24 \mathrm{~h}$ low temperatures, the FPKM of GSTU43 gene we measured. Data are expressed as the mean \pm standard error of three independent biological replicates. The experiments were repeated for three times. Different letters above the bars indicate a significant difference determined by one-way ANOVA with Tukey's test $(P<0.05)$. (JPG $886 \mathrm{~kb})$

Additional file 3: Figure S2. Characterization of tomato pTRV-GSTU43 plants and ALA induced changes of phenotypes and growth in GSTU43silenced plants under low temperature. (a) Expression of GSTU43 gene expression in pTRV and pTRV-GSTU43 plants. (b) The dry weight of plants. (c) The phenotypes of plants. The GSTU43 gene expression was measured at $35 \mathrm{~d}$ after infection. The gene transcription level in pTRV plants was normalized as 1. And then VIGS plants leaves were treated with distilled water or $25 \mathrm{mg} \cdot \mathrm{L}^{-1} \mathrm{ALA}$, subsequently exposed to normal condition $\left(22^{\circ} \mathrm{C} / 20^{\circ} \mathrm{C}\right.$, day/ night) or low temperature $\left(15^{\circ} \mathrm{C} / 8^{\circ} \mathrm{C}\right.$, day/ night) $12 \mathrm{~h}$ later. After $6 \mathrm{~d}$ of low temperature, the plants dry weight were measured 
and taken photos. Data are expressed as the mean \pm standard error of seven independent biological replicates. The experiments were repeated for three times. Different letters above the bars indicate a significant difference determined by one-way ANOVA with Tukey's test $(P<0.05)$, while ${ }^{\prime * * \prime}$ above the bars indicate a significant difference determined by one-way ANOVA with Tukey's test ( $P<0.01)$. (JPG $3827 \mathrm{~kb})$

\section{Abbreviations}

ALA: 5- aminolevulinic acid; APX: Ascorbate peroxidase; AsA: Ascorbate; CAT: Catalase; DHAR: Dehydroascorbate reductase; Fv/Fm: Maximal quantum yield of PSII photochemistry; GAB: Gabaculine; GR: Glutathione reductase; GSH: Glutathione; GST: Glutathione S-transferase; $\mathrm{H}_{2} \mathrm{O}_{2}$ : Hydrogen peroxide; MDA: Malondialdehyde; MDHAR: Monodehydroascorbate reductase; Mgproto IX: Mg-protoporphyrin IX; PBG: Porphobilinogen; Pchl: Protochlorophyll; Proto IX: Protoporphyrin IX; REC: Relative electrical conductivity; SOD: Superoxide dismutase; UROIII: uroporphyrinogen III

\section{Acknowledgements}

We thank Pro. Qingmei Guan and Dr. Dehui Zhang for their assistance of western blotting experiment; and thank Pro. Zhen Li, Hao Li, and Dr. Fang Ma, Jianhua Jia and Hao Sun for their assistance of VIGS experiment (College of Horticulture, Northwest A \& F University).

\section{Authors' contributions}

$T L, X H$ and $J$ designed the experiments and wrote the manuscript. $T L, Q D$, $S L, J Y, X L, J X$, and PC performed the experiments. TL and XH analyzed the data. All authors have read and approved the final version of the manuscript.

\section{Funding}

This work was supported by grants from the Key Research and Development Program of Shaanxi Province, China (2018TSCXL-NY-05-01), the China Agriculture Research System (CARS-23-C-05) and Northwest A \& F University Experimental Demonstration Station (base) Science and Technology Innovation and Achievement Transformation Project (TGZX2019-23). The funders had no role in the experiment design, data analysis, decision to publish, or preparation of the manuscript.

\section{Availability of data and materials}

The datasets analyzed during the current study are available from the corresponding author on reasonable request.

\section{Ethics approval and consent to participate}

Not applicable.

\section{Consent for publication}

Not applicable.

\section{Competing interests}

The authors declare that they have no competing interests.

\section{Author details}

${ }^{1}$ College of Horticulture, Northwest A \& F University, Yangling 712100, Shaanxi, China. ${ }^{2}$ Key Laboratory of Protected Horticultural Engineering in Northwest, Ministry of Agriculture, Yangling 712100, Shaanxi, China. ${ }^{3}$ Shaanxi Protected Agriculture Research Centre, Yangling 712100, Shaanxi, China.

Received: 23 October 2018 Accepted: 9 July 2019

\section{Published online: 18 July 2019}

\section{References}

1. Browse J, Xin Z. Temperature sensing and cold acclimation. Curr Opin Plant Biol. 2001;4(3):241-6

2. Nahar K, Hasanuzzaman M, Alam MM, Fujita M. Exogenous spermidine alleviates low temperature injury in mung bean (Vigna radiata L.) seedlings by modulating ascorbate-glutathione and glyoxalase pathway. Int J Mol Sci. 2015;16(12):30117-32.

3. Akram NA, Ashraf M. Regulation in plant stress tolerance by a potential plant growth regulator, 5-aminolevulinic acid. J Plant Growth Regul. 2013; 32(3):663-79.
4. An $Y Y$, Feng $X X$, Liu LB, Xiong $L J$, Wang $L J$. ALA-induced flavonols accumulation in guard cells is involved in scavenging $\mathrm{H}_{2} \mathrm{O}_{2}$ and inhibiting stomatal closure in Arabidopsis cotyledons. Front Plant Sci. 2016;7:1713.

5. Feng XX, An YY, Zheng J, Sun M, Wang LJ. Proteomics and SSH analyses of ALA-promoted fruit coloration and evidence for the involvement of a MADS-box gene, MdMADS1. Front Plant Sci. 2016;7:1615.

6. Korkmaz A, Korkmaz Y, Demirkıran AR. Enhancing chilling stress tolerance of pepper seedlings by exogenous application of 5-aminolevulinic acid. Environ Exp Bot. 2010;67(3):495-501.

7. Ali B, Xu X, Gill RA, Yang S, Ali S, Tahir M, Zhou WJ. Promotive role of 5aminolevulinic acid on mineral nutrients and antioxidative defense system under lead toxicity in Brassica napus. Ind Crop Prod. 2014;52:617-26.

8. Liu D, Kong DD, Fu XK, Ali B, Xu L, Zhou WJ. Influence of exogenous 5aminolevulinic acid on chlorophyll synthesis and related gene expression in oilseed rape de-etiolated cotyledons under water-deficit stress. Photosynthetica. 2016;54(3):468-74.

9. Li DM, Zhang J, Sun WJ, Li Q, Dai AH, Bai JG. 5-aminolevulinic acid pretreatment mitigates drought stress of cucumber leaves through altering antioxidant enzyme activity. Sci Hortic-Amsterdam. 2011;130(4):820-8.

10. Guo XQ, Li YS, Yu XC. Promotive effects of 5-aminolevulinic acid on photosynthesis and chlorophyll fluorescence of tomato seedlings under suboptimal low temperature and suboptimal photon flux density stressshort communication. Hortscience. 2012;39(2):97-9.

11. Sun XE, Feng XX, Li C, Zhang ZP, Wang LJ. Study on salt tolerance with YHem1 transgenic canola (Brassica napus). Physiol Plant. 2015;154(2):223-42.

12. Liu T, Hu XH, Zhang J, Zhang JH, Du QJ, Li JM. $\mathrm{H}_{2} \mathrm{O}_{2}$ mediates ALA-induced glutathione and ascorbate accumulation in the perception and resistance to oxidative stress in Solanum lycopersicum at low temperatures. BMC Plant Biol. 2018;18:34.

13. Foyer $\mathrm{CH}$, Noctor $\mathrm{G}$. Ascorbate and glutathione: the heart of the redox hub. Plant Physiol. 2011;155(1):2-18.

14. Ball L, Accotto GP, Bechtold U, Creissen G, Funck D, Jimenez A, Kular B, Leyland N, Mejia-Carranza J, Reynolds H, Karpinski S, Mullineaux PM. Evidence for a direct link between glutathione biosynthesis and stress defense gene expression in Arabidopsis. Plant Cell. 2004;16(9):2448-62.

15. Li H, He J, Yang XZ, Li X, Luo D, Wei CH, Ma JX, Zhang Y, Yang JQ, Zhang X. Glutathione-dependent induction of local and systemic defense against oxidative stress by exogenous melatonin in cucumber(Cucumis sativus L.). J Pineal Res. 2016;60:206-16.

16. Jiang YP, Cheng F, Zhou YH, Xia XJ, Mao WH, Shi K, Chen ZX, Yu JQ. Cellular glutathione redox homeostasis plays an important role in the brassinosteroid-induced increase in $\mathrm{CO}_{2}$ assimilation in Cucumis sativus. New Phytol. 2012;194(4):932-43.

17. Edwards R, Dixon DP, Walbot V. Plant glutathione S-transferases: enzymes with multiple functions in sickness and in health. Trends Plant Sci. 2000;5(5):193-8.

18. Dixon DP, Cummins I, Cole DJ, Edwards R. Glutathione-mediated glutathione-dependent in the detoxification compounds. Detoxification systems in plants. Curr Opin Plant Biol. 1998;1(3):258-66.

19. Nianiou-Obeidat I, Madesis P, Kissoudis C, Voulgari G, Chronopoulou E, Tsaftaris A, Labrou NE. Plant glutathione transferase-mediated stress tolerance: functions and biotechnological applications. Plant Cell Rep. 2017;36(6):791-805.

20. Csiszar J, Horvath E, Vary Z, Galle A, Bela K, Brunner S, Tari I. Glutathione transferase supergene family in tomato: salt stress-regulated expression of representative genes from distinct GST classes in plants primed with salicylic acid. Plant Physiol Biochem. 2014;78:15-26.

21. Sun W, Xu XN, Zhu HS, Liu AH, Liu LL, Li JM, Hua XJ. Comparative transcriptomic profiling of a salt-tolerant wild tomato species and a saltsensitive tomato cultivar. Plant Cell Physiol. 2010;51(6):997-1006.

22. George S, Venkataraman G, Parida A. A chloroplast-localized and auxininduced glutathione S-transferase from phreatophyte Prosopis juliflora confer drought tolerance on tobacco. J Plant Physiol. 2010;167(4):311-8.

23. Roxas VP, Lodhi SA, Garrett DK, Mahan JR, Allen RD. Stress tolerance in transgenic tobacco seedlings that overexpress glutathione $S$ - transferase/ glutathione peroxidase. Plant Cell Physiol. 2000;41(11):1229-34.

24. Takesawa T, Ito M, Kanzaki H, Kameya N, Nakamura I. Over-expression of $\zeta$ glutathione S-transferase in transgenic rice enhances germination and growth at low temperature. Mol Breeding. 2002;9:93-101.

25. Dixon DP, Lapthorn A, Madesis P, Mudd EA, Day A, Edwards R. Binding and glutathione conjugation of porphyrinogens by plant glutathione transferases. J Biol Chem. 2008;283(29):20268-76. 
26. Chen CY, Ho SS, Kuo TY, Hsieh HL, Cheng YS. Structural basis of jasmonate-amido synthetase FIN219 in complex with glutathione S-transferase FIP1 during the JA signal regulation. Proc Natl Acad Sci U S A. 2017;114(10):1815-24.

27. Dixon DP, Skipsey M, Edwards R. Roles for glutathione transferases in plant secondary metabolism. Phytochemistry. 2010;71(4):338-50.

28. Wang P, Grimm B. Organization of chlorophyll biosynthesis and insertion of chlorophyll into the chlorophyll-binding proteins in chloroplasts. Photosynth Res. 2015;126(2-3):189-202.

29. Lederer B, Böger P. Binding and protection of porphyrins by glutathione Stransferases of Zea mays L. BBA. 2003;1621(2):226-33.

30. Al-Ghamdi AA, Elansary HO. Synergetic effects of 5-aminolevulinic acid and Ascophyllum nodosum seaweed extracts on Asparagus phenolics and stress related genes under saline irrigation. Plant Physiol Biochem. 2018;129:273-84.

31. Niu KJ, Ma X, Liang GL, Ma HL, Jia ZF, Liu WH, Yu QQ. 5-Aminolevulinic acid modulates antioxidant defense systems and mitigates drought-induced damage in Kentucky bluegrass seedlings. Protoplasma. 2017;254(6):2083-94.

32. Sheteiwy M, Shen H, Xu JG, Guan YJ, Song WJ, Hu J. Seed polyamines metabolism induced by seed priming with spermidine and 5-aminolevulinic acid for chilling tolerance improvement in rice (Oryza sativa L.) seedlings. Environ Exp Bot. 2017;137:58-72.

33. Xiong JL, Wang HC, Tan XY, Zhang CL, Naeem MS. 5-aminolevulinic acid improves salt tolerance mediated by regulation of tetrapyrrole and proline metabolism in Brassica napus L. seedlings under $\mathrm{NaCl}$ stress. Plant Physiol Biochem. 2018;124:88-99.

34. Liu T, Xu JJ, Li JM, Hu XH. NO is involved in JA- and $\mathrm{H}_{2} \mathrm{O}_{2}$-mediated ALAinduced oxidative stress tolerance at low temperatures in tomato. Environ Exp Bot. 2019;161:334-43.

35. Czarnecki O, Gläßer C, Chen JG, Mayer KFX, Grimm B. Evidence for a contribution of ALA synthesis to plastid-to-nucleus signaling. Front Plant Sci. 2012;3:00236

36. Demko V, Pavlovič A, Hudák J. Gabaculine alters plastid development and differentially affects abundance of plastid-encoded DPOR and nuclearencoded GluTR and FLU-like proteins in spruce cotyledons. J Plant Physiol. 2010;167(9):693-700

37. Cheng F, Yin LL, Zhou J, Xia XJ, Shi K, Yu JQ, Zhou YH, Foyer CH. Interactions between 2-Cys peroxiredoxins and ascorbate in autophagosome formation during the heat stress response in Solanum lycopersicum. J Exp Bot. 2016;67(6):1919-33.

38. Ekengren SK, Lui Y, Schiff M, Dinesh-Kumar SP, Martin GB. Two MAPK cascades, NPR1, and TGA transcription factors play a role in pro-mediated disease resistance in tomato. Plant J. 2003;36(6):905-17.

39. Strain $\mathrm{HH}$, Svec WA. Extraction, separation, estimation and isolation of the chlorophylls. In: Vernon LP, Seeley GR, editors. The chlorophylls. New York: Academic Press; 1966. p. 21-66.

40. Morton RA. Biochemical spectroscopy: a. Hilger; London; Bristol; 1975. p. 1.

41. Bogorad L. Methods in Enzymology, vol. 5. San Diego, New York, Berkeley, Boston, London, Sydney, Tokyo: Toronto Academic Press; 1962. p. 885-95.

42. Hodgins R, Van Huystee R. Rapid simultaneous estimation of protoporphyrin and mg-porphyrins in higher plants. J Plant Physiol. 1986;125:311-23.

43. Li JM, Hu LP, Zhang L, Pan XB, Hu XH. Exogenous spermidine is enhancing tomato tolerance to salinity-alkalinity stress by regulating chloroplast antioxidant system and chlorophyll metabolism. BMC Plant Biol. 2015;15:303.

44. Willekens $\mathrm{H}$, Chamnongpol S, Davey M, Schraudner M, Langebartels C, Montagu MV, Inzé D, Camp WV. Catalase is a sink for $\mathrm{H}_{2} \mathrm{O}_{2}$ and is indispensable for stress defence in $C_{3}$ plants. EMBO J. 1997;16(16):4806-16.

45. Hodges DM, DeLong JM, Forney CF, Prange RK. Improving the thiobarbituric acid-substances assay for estimating lipid peroxidation in plant tissues containing anthocyanin and other inerfering compounds. Planta. 1999;207:604-11.

46. Zhou WJ, Leul M. Uniconazole-induced alleviation of freezing injury in relation to changes in hormonal balance, enzyme activities and lipid peroxidation in winter rape. Plant Growth Regul. 1998;26:41-7.

47. Perez-Bueno ML, Pineda M, Diaz-Casado E, Baron M. Spatial and temporal dynamics of primary and secondary metabolism in phaseolus vulgaris challenged by pseudomonas syringae. Physiol Plant. 2015;153(1):161-74.

48. Giannopolitis CN, Ries SK. Superoxide dismutases I. Occurrence in higher plants. Plant Physiol. 1977;59:309-14.

49. Noctor G, Mhamdi A, Foyer CH. Oxidative stress and antioxidative systems: recipes for successful data collection and interpretation. Plant Cell Environ. 2016;39(5):1140-60.

50. Vandesompele J, Preter KD, Pattyn F, Poppe B, VanRoy N, Paepe AD, Speleman F. Accurate normalization of real-time quantitative RT-PCR data by geometric averaging of multiple internal control genes. Genome Biol. 2002;3(7):0034.

51. Livak KJ, Schmittgen TD. Analysis of relative gene expression data using realtime quantitative PCR and the $2^{-\Delta \Delta C}$ method. Methods. 2001;25(4):402-8.

52. Zhou J, Xu XC, Cao JJ, Yin LL, Xia XJ, Shi K, Zhou YH, Yu JQ. Heat shock factor HsfAla is essential for $\mathrm{R}$ gene-mediated nematode resistance and triggers $\mathrm{H}_{2} \mathrm{O}_{2}$ production. Plant Physiol. 2018;176(3):2456-71.

53. Ali B, Wang B, Ali S, Ghani MA, Hayat MT, Yang C, Xu L, Zhou WJ. 5aminolevulinic acid ameliorates the growth, photosynthetic gas exchange capacity, and ultrastructural changes under cadmium stress in Brassica napus L. J Plant Growth Regul. 2013;32(3):604-14.

54. Da QG, Wang P, Wang ML, Sun T, Jin HL, Liu B, Grimm B, Wang HB. Thioredoxin and $\mathrm{NADPH}$-dependent thioredoxin reductase $\mathrm{C}$ regulation of tetrapyrrole biosynthesis. Plant Physiol. 2017;175(2):652-66.

55. Apitz J, Nishimura K, Schmied J, Wolf A, Hedtke B, van Wijk KJ, Grimm B. Posttranslational control of ALA synthesis includes GluTR degradation by Clp protease and stabilization by GluTR-binding protein. Plant Physiol. 2016; 170(4):2040-51.

56. Dietz K, Mittler R, Noctor G. Recent progress in understanding the role of reactive oxygen species in plant cell signaling. Plant Physiol. 2016;171(3):1535-9.

57. Foyer $\mathrm{CH}$, Noctor G. Stress-triggered redox signalling: what's in pROSpect? Plant Cell Environ. 2016;39(5):951-64.

58. Zhu JK. Abiotic stress signaling and responses in plants. Cell. 2016; 167(2):313-24.

59. Xia XJ, Fang PP, Guo X, Qian XJ, Zhou J, Shi K, Zhou YH, Yu JQ. Brassinosteroid-mediated apoplastic $\mathrm{H}_{2} \mathrm{O}_{2}$-glutaredoxin 12/14 cascade regulates antioxidant capacity in response to chilling in tomato. Plant Cell Environ. 2017:41(5):1052-64.

60. Zhu XJ, Liao JR, Xia XL, Xiong F, Yue L, Shen JZ, Wen B, Ma YC, Wang YH, Fang WP. Physiological and iTRAQ-based proteomic analyses reveal the function of exogenous $\gamma$-aminobutyric acid (GABA) in improving tea plant (Camellia sinensis L.) tolerance at cold temperature. BMC Plant Biol. 2019;19:43.

61. Li XN, Brestic M, Tan DX, Zivcak M, Zhu XC, Liu SQ, Song FB, Reiter RJ, Liu FL. Melatonin alleviates low PS I-limited carbon assimilation under elevated $\mathrm{CO}_{2}$ and enhances the cold tolerance of offspring in chlorophyll b-deficient mutant wheat. J Pineal Res. 2018;64:e12453.

62. Wang $L$, Jiang WB, Huang BJ. Promotion of 5 -aminolevulinic acid on photosynthesis of melon (Cucumis melo) seedlings under low light and chilling stress conditions. Physiol Plant. 2004;121:258-64.

63. Mochizuki N, Tanaka R, Tanaka A, Masuda T, Nagatani A. The steady-state level of mg-protoporphyrin IX is not a determinant of plastid-to-nucleus signaling in Arabidopsis. Proc Natl Acad Sci U S A. 2008;105(39):15184-9.

64. Niu KJ, Ma HL. The positive effects of exogenous 5-aminolevulinic acid on the chlorophyll biosynthesis, photosystem and Calvin cycle of Kentucky bluegrass seedlings in response to osmotic stress. Environ Exp Bot. 2018;155:260-71.

65. Stenbaek A, Jensen PE. Redox regulation of chlorophyll biosynthesis. Phytochemistry. 2010;71(8-9):853-9.

66. Larkin RM. Tetrapyrrole signaling in plants. Front Plant Sci. 2016;7:1586.

67. Zhang ZW, Yuan S, Xu F, Yang H, Chen YE, Yuan M, Xu MY, Xue LW, Xu XC, Lin $\mathrm{HH}$. Mg-protoporphyrin, haem and sugar signals double cellular total RNA against herbicide and high-light-derived oxidative stress. Plant Cell Environ. 2011;34(6):1031-42.

68. Dixon DP, Steel PG, Edwards R. Roles for glutathione transferases in antioxidant recycling. Plant Signal Behav. 2011;6(8):1223-7.

69. Willems P, Mhamdi A, Stael S, Storme V, Kerchev P, Noctor G, Gevaert K, Van Breusegem F. The ROS wheel: refining ROS transcriptional footprints. Plant Physiol. 2016;171(3):1720-33.

70. Mittler R. Oxidative stress, antioxidants and stress tolerance. Trends Plant Sci. 2002;7(9):405-10.

\section{Publisher's Note}

Springer Nature remains neutral with regard to jurisdictional claims in published maps and institutional affiliations. 